\title{
Una poética del nombre: los "comienzos" de María Moreno hacia mediados de los años 80 en el contexto cultural argentino*
}

\author{
Lucía María de Leone
}

\begin{abstract}
Resumen
Este trabajo aborda el periódico alfonsina y el suplemento "La Mujer" del diario Tiempo argentino, dos publicaciones feministas argentinas contemporáneas, dirigidas por María Moreno. Ambas surgen a principios de los años 80, que fueron marcados por el ocaso de la dictadura militar y el renacer político, institucional y cultural de la transición democrática. En ese contexto, Moreno opta por tematizar y desafiar en dichas publicaciones -que se pretenden precursoras respecto de la tradición de periodismo para mujeres- sus propios "comienzos". En ellos se cifran ciertas negociaciones "necesarias" que hacen a las posiciones de un mismo sujeto femenino y que pareciera en ese entonces tener que astillarse o recurrir a operaciones de reversibilidad de género (gender) o ideológica para autorizar su "entrada a la escritura".
\end{abstract}

Palauras-chave: María Moreno, Auto-figuración, Prensa Feminista, Argentina (Siglo XX).

\footnotetext{
* Recebido para publicação em maio de 2010, aceito em março de 2011.

"** Profesora de Letras, egresada de la Facultad de Filosofía y Letras de la Universidad de Buenos Aires. Investigadora del Instituto Interdisciplinario de Estudios de Género (IIEGE) y del Instituto de Literatura Hispanoamericana (ILH), Facultad de Filosofía y Letras, UBA. Becaria doctoral del CONICET (Consejo Nacional de Investigaciones Científicas y Técnicas).

lmdeleone@gmail.com
}

cadernos pagu (36), janeiro-junho de 2011:223-256. 
Una poética del nombre

A Poetics of the Name:

Maria Moreno's "Beginnings" in the Mid-Eighties in the Argentinean Cultural Context

\begin{abstract}
This paper analyses the newspaper alfonsina and the supplement "La Mujer" of Tiempo Argentino, two contemporary Argentinean feminist publications, directed by Maria Moreno. Both arise at the beginning of the eighties, marked by the decline of military dictatorship and the political, institutional and cultural revival of democratic transition. In that context, Moreno chooses to challenge in both journals - which claimed to be forerunners with respect to the traditions of journalism for women - her own "beginnings". They involve "necessary" negotiations relative to the same feminine subject that at the time seemed to have to either splinter or ideologically resort to gender reversibility in order to authorize her "entry into writing".
\end{abstract}

Key Words: María Moreno, Self-figuration, Feminist Press, Argentina (XXth. Century). 
Lucía María de Leone

\section{Preliminares}

La escritora y periodista argentina María Cristina Forero firma hoy todos sus textos como "María Moreno". Esa fórmula nominal, que combina un nombre de pila real (María) con el apellido tomado de un "marido de entonces" (Moreno, 2005:13), el periodista Marcelo Moreno. Esa fórmula se ha convertido hoy en una función del discurso, en un nombre de autora, que "asegura una función clasificatoria; (...) permite reagrupar cierto número de textos, delimitarlos, excluir algunos, oponerlos a otros" (Foucault, 1984:94 [1969]). Se trata de una serie de palabras que adquiere una manera singular de decodificación y de circulación y un estatuto diferente al del nombre propio, sea éste el oficial, el elegido, el inventado.

Antes de sentar cabeza como "María Moreno", antes de que el seudónimo se volviera un nombre, la auto-rebautizada Moreno, que cuenta hoy con una trayectoria de más de tres décadas en el periodismo cultural argentino y en publicaciones relativas a la mujer, ha ido desplegando en su heterogénea producción periodística y ficcional, diversos modos de autofiguración autoral ${ }^{1}$, es decir, múltiples formas, unas más veladas que otras, de nombrarse, de representarse o mejor, de crearse a sí misma como autora. La categoría de autora que utilizamos es cercana a las formulaciones de Julio Premat (2006, 2009), quien propone una renovada mirada sobre el concepto de "autor", definido no en términos de un sujeto empírico sino como un "espacio conceptual", una construcción social $e$ imaginaria y, al mismo tiempo, un "efecto textual", desde el cual resulta fructífero reflexionar sobre numerosas características de las prácticas de escritura en contextos determinados.

1 Para el concepto de "autofiguración" me baso preferentemente en los trabajos de Sylvia Molloy (1991), de María Teresa Gramuglio (1992) y de Julio Premat (2006, 2009). 
Una poética del nombre

En esta ocasión, me centraré preferentemente en las intervenciones de Moreno en el periódico alfonsina y, en menor medida y como contrapunto, en el suplemento "La Mujer" del diario Tiempo Argentino, para pensarlas como "los comienzos" de María Moreno. Si bien esas actuaciones no corresponden estrictamente a los inicios cronológicos de la actividad profesional de María Moreno, ${ }^{2}$ delinean, como veremos, una zona desde la cual se tematiza, se problematiza y, así, se desnaturaliza una idea de comienzo, y demarcan también un espacio de experimentación estética que sella en adelante su escritura.

La elección del corpus y su puesta en relación no son azarosas. A nivel contextual, se trata de dos publicaciones contemporáneas que surgen en los primeros años de 1980, marcados por el ocaso de la dictadura militar (que se impuso en Argentina de 1976 hasta 1983) y el renacer político, institucional y cultural, que se activan con la transición democrática. Ambas presentan características en común, son afines en su tendencia (programática $e$ intelectual) y en la composición de su staff, y coinciden en el tratamiento de las temáticas más actuales de la agenda del feminismo de entonces. Ahora bien, los aspectos que más interesan a esta lectura son, por un lado, que tanto en el periódico como en el suplemento, ideados y dirigidos por la propia Moreno, pese a la extensa tradición argentina de publicaciones de y para mujeres, ${ }^{3}$ se advierte, aunque con distintas entonaciones, una voluntad precursora a propósito del periodismo "para mujeres". Así, mientras alfonsina se autodefine desde la portada como el "primer periódico para mujeres" y tematiza ese gesto inaugural a lo largo de las sucesivas entregas, el suplemento "La Mujer", si bien no cuenta con un enunciado tan

2 Su trayectoria periodística se inaugura en los años 70 en el diario La Opinión; allí, firmaba con su nombre real (María Cristina Forero). En las revistas Vogue y Siete Días hizo su aparición pública como María Moreno.

3 Utilizo el sintagma "para mujeres" de manera general para referirme a la larga tradición argentina de periodismo y feminismo. Ver Néstor Tomás Auza (1998) y Graciela Batticuore (2005). 
explícito, ha sido considerado una de las primeras secciones feministas argentinas de la época, insertas en un medio gráfico de alcance masivo. ${ }^{4}$ Por otra parte, estos comienzos, reiventados o impostados, parecieran funcionar retrospectivamente como un espacio privilegiado en el que es posible advertir un punto de crispación de sus modos de figuración autoral, una marca definitiva del proyecto de escritura de Moreno, de los que se empieza a dar pistas en las trampas con el nombre (ni más ni menos que una carta de presentación fundamental), y que, como se irá detallando, van a ir asumiendo distintas formas.

En el marco del fenómeno del "destape" (institucional, sexual, judicial) de inicios de la década del 80 y de los entusiasmos que trae la democracia recién recuperada, ese impulso de Moreno por instalar una suerte de nuevo "comienzo" en el periodismo "para mujeres" en el contexto de un renacer político-cultural se cruza y coincide con el "destape" de las estrategias de exhibición, manipulación u ocultamiento de la firma de autor y de la identidad textual de la protagonista y mentora de ambas publicaciones. En estos comienzos se cifran las apuestas de Moreno pero también se juegan ciertas negociaciones "necesarias"

4 Si bien en el diario La Opinión ya existía una página dirigida a las mujeres a cargo de Felisa Pinto, en la que Moreno hace sus primeras incursiones, y como explica Soledad Vallejos (2006) ésta se pensaba como un espacio de resistencia femenina, las problemáticas de tinte feminista estaban aún amalgamadas con las temáticas más estereotipadas y tradicionales de las revistas para la mujer. A propósito de la novedad que trae el suplemento "La Mujer" pueden consultarse varios textos. Entre ellos, el de Vanina Escales donde se comenta: "En el diario Tiempo Argentino (María Moreno) tenía una columna llamada "A tontas y a locas" en donde se hacía la loca y la nena como si no lo fuera, pero también tenía a su cargo el suplemento "La Mujer", el único feminista de la época". A su vez, las declaraciones de Pablo Sirvén (un crítico de espectáculos de Tiempo Argentino) sobre el suplemento "La Mujer", al que concibe como un suplemento declaradamente feminista, moderno y diferente, pueden consultarse en Carlos Ulanosky (1997; 2005:147). Por último, Lea Fletcher (2007:88-89) afirma que: "("La Mujer") comenzó con tres páginas y llegó a tener once. Una sección fija del suplemento - una novedad en el periodismo femenino y feminista- era la tira cómica a cargo de Diana Raznovich". 
Una poética del nombre

que hacen a las posiciones de un mismo sujeto femenino, que, como veremos, pareciera en ese entonces tener que astillarse o recurrir a operaciones de reversibilidad (Russotto, 2006) de género (gender) o ideológica para autorizar su "entrada a la escritura".

Antes del análisis de los modos de construcción de un "yo" autoral de María Moreno en relación con el comienzo de un proyecto periodístico y de escritura, se propone, a modo de presentación, un breve recorrido por la historia y el programa de ambas publicaciones y una reconstrucción parcial de su circulación. Más adelante, en el apartado "La voluntad de comenzar" se examina, a partir de las formulaciones sobre los comienzos de Edward Said en Beginnings. Intention and Method $(1975 ; 1985)$ y de Roland Barthes en La preparación de la novela. Notas de cursos y seminarios en el Collège de France, 1978-1979 y 1979-1980 (2005), las resonancias del gesto inaugural de Moreno preferentemente en alfonsina. En la sección "Poética del nombre" se presenta un análisis de las estrategias de auto-figuración de María Moreno que "estallan", por primera vez de esa manera, en alfonsina y "La mujer" y dejan una marca en la "obra por hacer", y por eso permiten delinear allí sus comienzos.

\section{En torno de alfonsina y "La Mujer"}

A partir del 15 de diciembre de 1983, cuando Raúl Alfonsín ya era oficialmente el presidente de los argentinos, en los puestos de periódicos de Buenos Aires y del interior, se vende alfonsina, el autodesignado "primer periódico para mujeres". Se trata de un periódico en blanco y negro, de periodicidad quincenal en los primeros números y luego mensual, de una editora pequeña $e$ independiente, ${ }^{5}$ y caracterizado por una tendencia feminista

\footnotetext{
5 Galanternik Comunicaciones S.A., que en ese entonces editaba y producía también la revista Twist y gritos.
} 
menos académica y política procedente del "under porteño" ${ }^{6}$ que necesariamente predispone un público lector y que pone en serie la publicación con el movimiento artístico urbano del "under", característico de esos años del destape, con cuyos representantes, la misma Moreno había estado vinculada, como con la actriz y performer travesti Batato Barea.

Aunque el periódico dice depender de esas mujeres que "han pensado la femineidad como una diferencia dramáticamente cultural" (Estado civil. alfonsina, 22/03/1984:16), lo que colocaría al periódico entre los partidarios de lo que en sus mismas páginas se denomina la "causa femenina", ambiciona tener una recepción más vasta y ser de y para todas las mujeres (Las mujeres siempre fuimos 'subte', alfonsina, 09/02/1984). Carlos Galanternik, el director editorial responsable, decide llevar adelante el proyecto cultural de la propia María Moreno, quien desde el segundo número y hasta el cierre, a mediados de 1984, asume con ese mote la dirección periodística.

Por su parte, el suplemento semanal "La Mujer" de Tiempo Argentino se presenta como una sección más de un matutino importante, de alcance masivo, costeado por un grupo económico sólido -entre otros, el Grupo Bridas de Carlos Bulgheroni- y que tuvo un tiempo más extendido de vida: entre 1982, casi un año antes de la salida del primer número de alfonsina, y 1986. Este periódico se distinguió por la multiplicidad de secciones $y$ suplementos, ${ }^{7}$ lo que nos hace sospechar un público lector amplio, heterogéneo, quizá incluso consumidor involuntario de "La Mujer". Esta sección contaba con un diseño sofisticado, con pinceladas fucsias en su portada, y estaba enteramente a cargo de María Moreno, cuya presencia en Tiempo Argentino, sin embargo, excedía la conducción de estas "páginas de la mujer". Moreno

6 En una entrevista María Moreno dice: "Creo que mi marca, de todos modos, viene más del under porteño que del feminismo académico o político" (Link, 2001).

7 Raúl Horacio Burzaco, su director desde su fundación, alude al formato de multimedia de Tiempo Argentino. Véase Ulanosky, Carlos (2005). 
Una poética del nombre

(con firma y con foto) escribía en ese mismo diario la columna "A tontas y a locas" en la sección dominical, no feminista ni orientada a la mujer, "Nuestro Tiempo", y hasta llegó a ocupar la Secretaría de Redacción.

Una serie de secciones $y$, en especial, los editoriales, firmados algunas veces por "alfonsina" con "a" minúscula y otras con "A" mayúscula, habilitan el espacio donde, entre humorística y programáticamente, se deja asentada la tendencia de alfonsina. La condición política y económicamente independiente del periódico - que a partir de la cuarta entrega deja ver algunos avisos publicitarios- se aclara, entre otras, en la sección "Estado Civil", cuyo slogan es "el diario que no se casa con nadie". Allí encontramos declaraciones de los propios editores que definen a alfonsina bien lejos del afán de las empresas periodísticas de "reproducir capital merced a una demanda popular" (Estado civil. alfonsina, 22/03/1984:16). ${ }^{8}$ También, algunos editoriales distinguen a alfonsina como una publicación "underground" (o "subte" en su "variante porteño criolla") que no está sostenida políticamente por ningún partido, y que, aunque cuenta con un número moderado de lectores, 9 "no está dispuesta a participar de ningún show del horror para vender más" (Estado civil. alfonsina, 22/03/1984). ${ }^{10}$ Esa puesta en escena del espanto es la crítica de alfonsina al fenómeno del "destape" con fines comerciales, que muchos medios (por ejemplo, se nombra a la revista La Semana) proponen de los cuerpos "destapados" de mujeres y que, en el entonces reciente contexto de la desaparición de personas, no puede sino tratarse de un destape asimétrico, el de la bella imagen, que tapa otras bocas. Por eso, en el editorial "La tortura como pornografía" Moreno,

8 Véanse también las declaraciones de Carlos Galanternik: "Fueron golpes de pasión, sin un plan de marketing que las hiciera viable" en Moreno, María. "La voz del estadio". "Radar", Página 12, 17/11/2002.

9 “... hasta ahora nos leen sólo unas 15.000 personas”. s/f. Estado civil. alfonsina, 22/03/1984:16.

${ }^{10}$ Las itálicas son del original. Cf. el editorial Las mujeres siempre fuimos 'subte'. alfonsina, 9/02/1984. 
una vez más como "alfonsina", imputa "a una prensa que ofertaba, en el 'quien da más' de un mismo número, el topless marplatense y las confesiones del torturador Villarino" (Moreno, 2001).

Así como la declaración de principios del periódico se advierte en los editoriales, la circulación de alfonsina puede reconstruirse, en parte y conjeturalmente, mediante las cartas de lectores, las que, podemos aventurar, eran parte de un proceso de selección y/o edición. Además de poseer una recepción esperable, acotada a un "entre nos" intelectual y de adhesión al feminismo, como las representantes de sitios vinculados a la mujer ${ }^{11}$ o lectores expertos - como el escritor argentino Rodolfo Fogwill -, en el periódico se activan otros modos de circulación que merecen destacarse: desde la recomendación del boca a boca entre "amigas pensantes", que vislumbran la dimensión de la "patriada" que esta publicación representa, hasta lectores impensados y revulsivos como Miguel Paulino Tato ${ }^{12}$ (el censor de películas durante la dictadura) o lectores ocasionales como Antonio Mucci, el ministro de trabajo del gobierno de Alfonsín, a quien los editores encuentran de casualidad en "La Paz" (el bar/oficina de la avenida Corrientes en Buenos Aires que era frecuentado por muchos periodistas de la época), y le hacen entrega de un ejemplar, o como esa mujer que fortuitamente se tropieza con la publicación en la sala de espera de un dentista. Una lectora absolutamente accidental, entonces, que en nada se le parece al modelo de lectora virtual delineado por el periódico - esas mujeres "que detestan las revistas femeninas, o que simplemente no se identifican con ellas" (Las mujeres siempre fuimos 'subte'. alfonsina,9/02/1984) - pero que, sin embargo, se siente interpelada por alfonsina y envía una carta a la editorial. En esa carta, confiesa

${ }^{11}$ Por ejemplo, Hilda Rais, de Lugar de Mujer. Ver: http://www.lugardemujer.org.ar

${ }^{12}$ Tal vez sea una ironía de los editores, que justamente el censor del Ente de Calificaciones se vislumbre y compre alfonsina. 
Una poética del nombre

su entusiasmo por la nueva publicación, pese a no haber entendido "ni medio" la polémica sobre el aborto. La mayoría de las entrevistas ocupan en alfonsina la zona denominada "Personas" y están dirigidas a gente vinculada a la cultura y al espectáculo y a activistas feministas y/o políticas e intelectuales destacadas (María Elena Walsh, Marie Langer, María Isabel de Mariano de "Abuelas", Hebe de Bonafini, una de las fundadoras de la asociación "Madres de Plaza de Mayo"). Los apartados "Secretaire", donde leemos una traducción de las conversaciones entre Simone de Beauvoir y Sartre sobre feminismo y donde suelen reproducirse notas de actualidad femenina de medios internacionales, ${ }^{13}$ que dan cuenta no sólo del impacto en la publicación de los debates más recientes del feminismo sino también de un diálogo abierto con ciertos medios de México, que fue uno de los países donde se refugiaron muchos exilados argentinos durante la última dictadura militar; ${ }^{14}$ la columna "Edictos policiales", en la que la firma "Rosa L. de Grossman" suscribe petitorios que ponen en tela de juicio resoluciones policiales y contravencionales vinculadas a la diversidad sexual; y las tiras de humor gráfico de Diana Raznovich completan, entre otras, las secciones de alfonsina.

En "La Mujer" colaboran muchos de los periodistas y artistas que en paralelo lo hacen en alfonsina. Tanto el formato como el tratamiento y el tipo de temáticas abordadas en el periódico y en el suplemento son semejantes. No es extraño encontrarse, en números que salen en simultáneo, con notas similares (e incluso las mismas) en una y otra publicación. Una práctica que entra en consonancia con el "vicio" con el que Moreno define -aunque a posteriori- su preparatoria de escritura: sufrir "poco la angustia de las influencias" y ser "una experta en el plagio" (Moreno, 2007:71) pero con la delicadeza de confesar que,

${ }^{13}$ Por ejemplo, Fotomagazine y Fempress.

${ }^{14}$ Algunas de las colaboradoras de la publicación, habían regresado hacía poco tiempo del exilio. 
si de robar se trata, ella prefiere volver a las fuentes y robarse a sí misma (Moreno, 2002:9).

Tal es el caso de la reproducción en alfonsina de la nota suscrita por María Moreno en Tiempo Argentino, en la que se cuestionan las declaraciones del Presidente en razón de su posible encuentro con Thatcher. Para responder a la frase de Alfonsín "con las mujeres es difícil discutir: me gustaría más encontrarme con el señor Thatcher" (Casas,1984:3), Moreno pone en uso su "técnica de cartonera" (Moreno, 2002:9) y traslada de "La Mujer" a alfonsina la nota en que escribe que "querer hablar con un gentleman es muy sospechoso", le recuerda a Alfonsín que han sido las mujeres sus principales votantes y lo acusa de caer en un "simple lugar misógino" en lugar de dedicar su política a "defender los intereses del pueblo". ${ }^{15}$

Por último, es notorio que frente a las muchas coincidencias que las dos publicaciones presentan, que en ocasiones se traducen, como vimos, en un tráfico declarado de artículos y de colaboradores, la periodicidad y la duración en la escena periodística argentina y también el financiamiento y la circulación se constituyen en factores que las diferencian. La última aparición de alfonsina data de junio de 1984 y antecede en casi dos años al conflictivo y definitivo cierre del diario Tiempo Argentino y, por ende, del suplemento "La Mujer", que tiene lugar en septiembre de 1986.

Si bien ya había publicado con anterioridad, habría que decir que es con su participación protagónica en alfonsina y "La Mujer", textualidades que ponen en discurso y desafían una idea de comienzo, que se produce el ingreso definitivo de Moreno en la escritura. Este ingreso puede leerse, al menos, en dos dimensiones o niveles complementarios: en aquello que, siguiendo a Said (1975; 1985), entendemos como "la voluntad" y "la intención" de comenzar, que en el marco del periódico y el suplemento se trataría de un comienzo sobredeterminado; y en aquello que, de

${ }^{15}$ Moreno (1984:2). Se reproduce consignando la fuente en alfonsina, 9/02/1984. 
Una poética del nombre

acuerdo con Barthes (2005), sería un "arranque por cristalización", es decir uno de los tipos posibles de modalidad de arranque de la escritura y que, en el caso de María Moreno, entendemos a partir de sus juegos de figuración autoral, que forman sistema, por vez primera y de manera exacerbada, en dichas publicaciones periódicas.

\section{La voluntad de comenzar}

Según Said (1985:34), la voluntad y el convencimiento de que empezar es posible, aun a sabiendas de los riesgos y las dificultades que implique, son precisamente condiciones habilitantes para que "algo" sea plausible de pensarse como un comienzo.

Esta "intención" y esta "conciencia" de comenzar quedan más explícitas en alfonsina que en "La Mujer", con el propósito de dar a conocer un periódico "hecho desde el punto de vista de la mujer"16 y, especialmente, mediante el enunciado "primer periódico para mujeres". A primera vista, este enunciado parecería querer negar el tener el propósito de completar o de implementar una actitud correctiva respecto de toda una vasta tradición, incluso en la Argentina, de prensa "para mujeres", de la que hay evidencias, al menos, desde el siglo XIX. Una actitud correctiva que, acaso, sea la de asumir declaradamente un lugar de enunciación femenino, la de poner de relieve un conjunto de problemáticas aún pendientes, atravesadas en su mayoría por el par feminismo y política, o la puesta en serie de la tortura y la pornografía, los cuerpos escondidos de $\mathrm{NN}$ y los cuerpos al destape, los hijos desaparecidos y los fetos abortados que dé

\footnotetext{
${ }^{16}$ En el segundo número de alfonsina del 29/12/1983, p.10, Hilda Rais, representante de Lugar de Mujer, escribe una carta a la editorial en la que dice: "Leímos el primer número con mucho placer. Por fin un periódico para nosotras, las mujeres, hecho desde el punto de vista de mujer...".
} 
efectiva cuenta del proyecto de la publicación de articular "lo femenino con lo nacional". ${ }^{17}$

A partir de que empiezan a registrarse las primeras intervenciones de mujeres en el periodismo argentino, la utilización de seudónimos parece volverse una práctica recurrente. Como si el acceso y la participación de la mujer en la escritura y el lanzamiento de publicaciones periódicas de y para la mujer requirieran el enmascaramiento o el cambio de sexo en el nombre, vemos que, por ejemplo, "Cecilia" era seudónimo de Rosa Guerra, "Judith" encubría a Josefina Pelliza de Sagasti, "Daniel" y "Alvar" escondían a Eduarda Mansilla (Auza, 1998) y, ya en el siglo XX, "Tao Lao" era el nombre de varón que Alfonsina Storni usaba para firmar en La Nación.

La elección de "María Moreno" (recordemos que es un seudónimo) no sólo de titular el periódico sino también de rubricar los editoriales como "alfonsina" deja al descubierto operaciones propias de la instancia de los comienzos, ese punto de inflexión en el que el escritor traza con todo lo que lo antecede relaciones de continuidad, de descarte, o de una mezcla de ambos.

El incipit del editorial del número inaugural de alfonsina es sintomático en este sentido pues se abre con una pregunta: "¿Por qué?". Así se pone en evidencia un comienzo por la vacilación, a propósito de la cual se ensayan posibles respuestas. La pregunta de arranque, entonces, es "¿Por qué?" y, como no se trata de una pregunta con fines meramente retóricos, podrá ir llenándose de distintas maneras. Ante la duda de "cipor qué?" hacer "hoy" (en diciembre de 1983, en vísperas del nuevo año, ya en democracia, en este nuevo comienzo) este periódico, la réplica que la editorialista "alfonsina" ofrece es definitiva, por ejemplo, respecto de un posicionamiento de género (gender): como es posible "ser madre y ser mujer", "desde hoy vamos a implantar un alegre casamiento del horno con la máquina de escribir" y "de los anteojos 'de leer' con las agujas de crochet". Pero también es

${ }^{17}$ Son declaraciones de Moreno en Link, Daniel (2001). 
Una poética del nombre

decisiva en su posicionamiento ético-político: "porque deseamos luchar por el país en lugar de entregarle el cuerpo de nuestros hijos".

Es interesante, como lo hace Nelly Richard $(2008)^{18}$ preguntarse por la posibilidad de conciliación del sujeto del feminismo desunificado con la necesidad de alcanzar un nosotras colectivo para la lucha política. En el marco del proyecto de Moreno que apuesta al descentramiento, al nomadismo de la identidad enunciativa y enunciada, se recurre al colectivo "nosotras" para reposicionarse tácticamente. Se trata de un "nosotras" no proclive a la desunión que se utiliza para manifestar el programa de una publicación, para la cual declararse primera no implica la negación de una tradición de mujeres. ${ }^{19}$

Al identificarse con estas mujeres la editorialista pone en relación a un grupo heterogéneo y dispar (de mujeres reales y representadas), que va desde personajes bíblicos y legendarios primigenios hasta miembros de sus propias familia (sus madres) o mujeres que forman un colectivo indiferenciado (brujas), pasando por íconos literarios como la princesa de Darío, la costurerita de Carriego, y mártires de Woodstock como Janis Joplin.

En el mismo editorial ante el interrogante inicial "¿Por qué?" también se manifiesta que "porque hay nombres de mujeres que no necesitan apellidos (...) Porque si hubo una Alfonsina que entró al mar para buscar la muerte, miles de Venus saldrán de las mismas aguas para cantar al amor y a la vida". La atribución del

\footnotetext{
${ }^{18}$ Nelly Richard toma esta idea del sujeto que proponen las filosofías postmetafísicas y/o deconstructivistas para definir al sujeto del feminismo.

${ }^{19}$ La genealogía o tradición de mujeres a las que se alude en el editorial es heterogénea: las propias madres de ese nosotras hasta Eva (¿la bíblica?, ¿la peronista?, cambas?), Lilith (la primera esposa de Adán), brujas, la costurerita que dio el mal paso (el personaje de la poesía del escritor argentino Evaristo Carriego), la princesa que está triste del poema de Darío, Janis Joplin, Milonguita (mujer de barrio que se pierde por los vicios y luces de la ciudad, que se recoge en muchas letras de tango de las primeras décadas del siglo XX), Juana La Loca, entre otras.
} 
editorial a la firma alfonsina a secas, puede leerse también como un gesto de Moreno (en la página siguiente constatamos que "alfonsina" será una de sus firmas) que se traduce en un posicionamiento estético y político al decidir iniciar el proyecto de un "primer periódico para mujeres" por un lado mediante la inserción dentro de una extensa tradición del empleo del seudónimo para la firma femenina $\mathrm{y}$, por el otro, a partir de la apropiación del nombre de una de las pioneras en el proceso de profesionalización de la escritura femenina y de una de esas mujeres hoy ya despojadas para su reconocimiento del apellido paterno. Recordemos que, acaso en la misma línea, María Moreno abandona el "Forero" paterno para firmar todos sus textos y si bien se dice que el "Moreno" es una apropiación del apellido de "un marido de entonces" (el blanco de reproches que, cuenta Moreno, le hacen ciertas feministas) lo cierto es que se le anula el unitivo "de" civil conyugal y que, además, este seudónimo utilizado para entrar en la escena pública y producir "textos que le dan de comer", ${ }^{20}$ habilita un abanico de sugestivas reminiscencias mediante un juego de aliteración producido por la iteración de las "M" en posición inicial de palabra: al primer marido (pero también periodista Marcelo Moreno), al considerado primer periodista argentino (Mariano Moreno), a la íntima amiga de la escritora Colette (Marguerite Moreno), o a su propio hijo (Manuel Moreno). ${ }^{21}$

El dispositivo visual (una ilustración anónima) que acompaña al editorial entra en comunicación evidente, quizá irónica, con las zonas del editorial antes citadas. El dibujo muestra a una mujer que entrecruza, al menos, dos imágenes consabidas de mujer, y así su identidad, como el "yo" verbal inestable y a la vez multiplicado que anuncia la unión de la mujer doméstica con

${ }^{20}$ Sin título (entrevista con María Moreno). Radar Libros, Página 12, 14/6/1998. Consultado el 8/06/2008: http://www.pagina12.com.ar/1998/ suple/Libros/9806/98-06-14/nota1.htm

${ }^{21}$ Moreno, María. La chillona alegría de esa época. Clarín, 22/12/2001. 
Una poética del nombre

la mujer con escritorio, también se representa divisible y no sencillamente encasillable desde el punto de vista visual: el lirismo tardo-romántico ${ }^{22}$ que se desprende de la figura de la potencial suicida que camina con la cabeza agachada, por la orilla del mar, oliendo una rosa, entra en tensión con el prosaísmo del delantal de cocina que la misma mujer lleva sobreimpreso a su ropa. El diálogo de la ilustración con el texto escrito sigue sosteniéndose al mostrarse un ave de tamaño fuera de escala (tengamos presente la amplificación del yo textual hacia el nosotras) que sale de las olas como si fuera una apropiación o una copia (no prestigiosa) de la imagen consagrada de Venus naciendo del mar. El fin de una "Alfonsina", entonces, se constituye en un motor productivo en tanto pareciera poder despertar el nacimiento de otras alfonsinas que, como Venus, como alfonsina (con minúsculas), como el "nosotras", como María Moreno, canten también "al amor y a la vida".

Una respuesta doblemente significativa. Por un lado, se expone la arbitrariedad del acto de comenzar: desde el primer renglón del primer editorial, firmado por "alfonsina", se realiza una puesta en escena de cómo comenzar y se decide, entonces, iniciar el proyecto tomando como punto de partida posible la muerte pero también la trascendencia ganada por Alfonsina Storni, que incluso excedería la serie compuesta por su condición de madre soltera, mujer, escritora, poeta, periodista, defensora de los derechos de la mujer y del niño, suicida. Y, por el otro, ya desde esas primeras líneas, que versan sobre la necesidad o no de que el nombre de ciertas mujeres porten apellido, se anticipa una de las estrategias (precisamente, el juego con los nombres) que

22 Dice Beatriz Sarlo (1999: 78-85) respecto de los poemas de Alfonsina Storni: “... los poemas de ese libro (La inquietud del rosal, 1916) y muchos de los que le siguen hasta Mundo de siete pozos, de 1934, son un resumen de la retórica tardo-romántica, aprendida en lecturas escasas propias de una formación azarosa $e$ insegura. Maestra de provincia, Alfonsina no puede, en estos primeros años, ser otra cosa que una poetisa de mal gusto". 
definen el tono de la obra de Moreno y, también, sus gestos de figuración como autora.

A su vez, el primer número de alfonsina se abre con una entrevista, "La madre de todas nosotras", a un referente políticocultural fundamental para los hacedores y consumidores virtuales del periódico: María Elena Walsh, quien ha participado activamente "en todos estos años, civiles y militares en lo que, con un enorme esfuerzo de abstracción, se ha dado en llamar La Causa de las Mujeres o de la Condición Femenina..." (La madre de todas nosotras. alfonsina, 15/12/1983:4-5). Curiosamente, la entrevista, que desde el título coloca, mediante un nosotros inclusivo, a ciertas mujeres en posición de hijas, de discípulas, de continuadoras de María Elena Walsh, aunque aparece firmada por un "alfonsina" en minúscula (ocurrencia ortográfica que enfatiza el posicionamiento en el rol de progenie o aprendiz) deja ver en la fotografía que acompaña al texto el perfil de una joven María Moreno, que luce su flequillo característico y su inconfundible pose de entrevistadora: la de la mano derecha sujetando el mentón. Con ese gesto, el de firmar como "alfonsina" pero también dejarse ver mediante un dispositivo icónico e indicial, de alta referencialidad como la fotografía, se pondrían en conjunción dos maniobras: la remisión a la revista en su totalidad (María Moreno como "alfonsina", vale decir, como la cifra y el comienzo de la publicación "alfonsina") y una operación de homenaje y de identificación con una iconografía fuerte (Moreno, 2005:11): María Moreno como una versión actualizada o una remake de la "Alfonsina" real. Claro es que en diciembre de 1983 el guiño fundacional de Moreno se valga también de una estrategia de feminización, y así de identificación, para con el apellido del primer presidente constitucional luego de años de dictadura, Raúl Alfonsín, para bautizar al "primer periódico para mujeres". Y esta afirmación adquiere una mayor carga semántica si tenemos en cuenta que son las mujeres, que habían sido excluidas durante 
Una poética del nombre

muchos años de los derechos civiles, ${ }^{23}$ las que constituyeron la mayor parte del electorado que eligió a Raúl Alfonsín como el nuevo presidente constitucional. Así como en noviembre de 1951, cuando a nivel nacional se produce el primer ejercicio del sufragio por parte de las mujeres, más de la mitad del electorado femenino (exactamente el 51\%) se inclinó por Juan Domingo Perón, en el contexto del renacer democrático, luego de años de no practicar, tanto hombres como mujeres, el derecho al voto, son las mujeres la mayoría que opta por Alfonsín. Evidente e innegable, más allá de la rotulación de "independencia" económica y política que alfonsina se atribuye para sí, es el entramado de resonancias que va trazando el nombre que se escoge para titular al primer periódico para mujeres de la democracia.

Aunque el uso del seudónimo o los juegos de figuración autoral de Moreno, que la llevan incluso a crear heterónimos masculinos para suscribir algunas de sus intervenciones, poco tienen que ver con las operaciones de las escritoras argentinas decimonónicas, no dejan de insertarse dentro de una práctica común del periodismo general y especialmente del escrito por mujeres. De esta manera, al remedar su hacedora ese hábito tradicional, la radicalidad de la expresión "Primer periódico para mujeres", que como ha señalado Tania Diz (2011) podría obedecer a una actitud de entusiasmo o, incluso, de marketing, se relativizaría inexorablemente. Una gradual atenuación de esa voluntad rupturista, que se advierte también al recuperar las variantes lexicales que ese enunciado va incorporando. Ya en la

${ }^{23}$ La ley de sufragio universal se sanciona el 10 de febrero de 1912 durante la administración de Roque Sáenz Peña. Como el sufragio ya era universal (desde 1853 para todo el país y desde 1820 para Buenos Aires), aunque sólo para varones nativos y naturalizados y mayores de 18 años, las novedades que introduce esta ley son, por un lado, la obligatoriedad y la condición secreta del voto. El primer presidente elegido en el marco de la reforma política es Hipólito Yrigoyen en 1916. A nivel nacional, la mujer quedó excluida del ejercicio del sufragio hasta el 11 de noviembre de 1951. Ver: Mirta Zaida Lobato (et al). Historia con mujeres. Mujeres con Historia. Buenos Aires, Editorial de la Facultad de Filosofía y Letras, Universidad de Buenos Aires, 2008 (CD). 
segunda entrega, el enunciado "Primer periódico para mujeres" que ocupaba, casi como escapándose, el margen superior izquierdo, se corre hacia una posición central en la portada y con un agregado. Es, ahora, el "primer periódico quincenal para mujeres", donde la periodicidad restringe el alcance del adjetivo ordinal y vuelve menos extrema la propuesta. Desde el séptimo número, de marzo del 84, y hasta la última aparición, de junio del mismo año, se erradica dicho enunciado de la portada Y, como si aquel giro fundacional de Moreno, en lugar de negar un origen, una tradición, o una genealogía, fuera demostrativo de una voluntad y de una necesidad de renacimiento, estimulado por el fervor propio de la instancia de los comienzos. Así podría anexársele al mismo enunciado un sintagma (y en mirada retroactiva éste puede resultar muy evidente pero en su momento no lo era tanto), que le daría un mayor anclaje coyuntural: el primer periódico para mujeres de una democracia recién recuperada.

Los "arranques" de Moreno, entendidos éstos según la propuesta de Barthes (2005), integrarían uno de los regímenes o "modo de dificultad" de "la larga paciencia de fabricación" que implica "emprender la obra". Barthes desarrolla diversos tipos de arranque de una obra, motivados unos por situaciones de crisis (ya de índole personal, espiritual o anecdótica, ya de índole histórico-política) y otros, por el advenimiento del momento casi "mágico", iluminador, de la instancia de amalgama que denomina "Cuaja" (id.ib.:327). Si filiar los comienzos al mito romántico de la crisis del escritor como impulso para la escritura no puede sino resultar un recurso gastado, un "comodín" (id.ib.:326) fecundo que tiende a explicar con facilidad y ductilidad el arranque de la obra, en el caso de las publicaciones de Moreno, el fin de la dictadura militar y los comienzos de la democracia a secas funcionarían casi privilegiada, aunque tranquilizadoramente, como una causalidad a través de la cual se pone en marcha de la obra. Por eso, aquí se propone pensar esos comienzos, sin desligarlos de la peculiar coyuntura pero tampoco reduciéndolos a ella, cercanos a lo que 
Una poética del nombre

Barthes presenta como un "arranque por cristalización": un comienzo en el que, de pronto, las apuestas estéticas de Moreno, antes dispersas, ensayadas o, directamente, no inscriptas dentro de un proyecto de escritura mayor, "cambian de estado", encuentran el tono y, por fin, "cuajan".

$\mathrm{Si}$ en un primer nivel, los comienzos de Moreno se asentaban en la textualización de la intención de empezar, cuya radicalidad sufre, o mejor goza a lo largo de las sucesivas entregas de alfonsina de un proceso atenuador, la segunda dimensión puede leerse en que tanto alfonsina $\mathrm{y}$, en menor medida, "La mujer" funcionarían como los soportes privilegiados donde sus estrategias de auto-representación se crispan por primera vez, quizá más exacerbadamente que nunca después, y demarcan, entonces, un espacio donde se juegan y empiezan a cristalizar ciertas características que sellan de ahí en más la obra por escribir. Es así que sus operaciones de multiplicación del sujeto textual y de repliegue e inestabilidad de la firma autoral formarían parte de lo que provisoriamente podríamos llamar un "sistema Moreno" de construcción de una imagen de sí, en tanto se proyectan hacia otros textos posteriores, incluso ficcionales, pero debutan, "cuajan", adquieren la mayor visibilidad y comienzan a hacerse reconocibles en el periódico y en el suplemento.

\section{Una poética del nombre}

Casi veinte años después del cierre de alfonsina y de "La Mujer", María Moreno, en el prólogo al libro Confesiones de escritores: escritoras, arroja una hipótesis sobre las prerrogativas y las concesiones que una mujer asume cuando se lanza a la escritura: "Estoy convencida de que las mujeres entran a la escritura a través de determinadas transacciones, máscaras y operaciones teóricas de género" (1997:3). En la misma línea, en una entrevista actual retoma estas ideas: "Cuando una mujer 
empieza a escribir, hace operaciones ligadas al género: entre ellas, difuminarlo o negarlo" (Radar Libros, Página 12, 14/6/1998). ${ }^{24}$

Si encontrar un "sistema de nombres", provechosos, o dar con la invención del "buen Yo" son algunos de los "descubrimientos creativos" que, según Barthes (2005:329), hacen presión a la hora de arrancar efectivamente en ese momento de "excitación", propia a todo proceso de inauguración, la presentación y representación de sí misma mediante una red de nombres y seudónimos, de personajes y heterónimos, de múltiples "yo", incluso masculinos, rubricando sus propios textos, sería, entonces, uno de esos "hallazgos" o "desencadenantes", mencionados por Barthes para pensar la instancia del empezar, que ponen en marcha la escritura de María Moreno.

Como se dijo, en alfonsina y el suplemento "La Mujer", además de redactora, María Moreno ocupa cargos directivos y espacios de poder y decisión. Tal vez como en ninguna otra oportunidad, sus intervenciones se encauzan mediante un juego sin fisuras de exhibición y disimulo de la firma autoral. Un gesto que, como parte de la poética de Moreno, pareciera irradiarse hacia el resto de los colaboradores de esas mismas publicaciones. Una irradiación de la que, sospechamos, Moreno no puede ni seguramente quiere ser del todo ajena. En alfonsina, el escritor argentino Néstor Perlongher se trasviste en Rosa L. de Grossman, un nombre que, al tiempo que homenajea a Rosa Luxemburgo, ${ }^{25}$ ensambla el convencionalmente muy femenino "rosa" más todas sus connotaciones de retórica romántica con el "hombre bruto" cifrado en el "Grossman", al que Rosa L. ("de") pareciera pertenecer, al menos civilmente; el cronista Martín Caparrós idea

${ }^{24}$ Más recientemente, Alberto Giordano (2008:60-64) reflexiona sobre los riesgos y los privilegios del ingreso de María Moreno a la cultura, una entrada escurridiza y difícil de precisar quizá por querer conservar activos "la ambición y el fervor irreverente de los comienzos".

${ }^{25}$ Moreno, María. Una lengua política. Soy. Página 12, 21 de marzo de 2008: "Néstor Perlongher, que solía firmar sus escritos políticos como Rosa L. de Grossman en homenaje a Rosa Luxemburgo...". 
Una poética del nombre

junto a Moreno a la periodista apócrifa Rosa Montana para suscribir, por ejemplo, una nota sobre una razzia policial ocurrida en democracia. ${ }^{26}$ Carlos Galanternik, pese a que en alfonsina firma con su nombre real, o a lo sumo con sus iniciales, ha creado para su figuración pública una fórmula que nos recuerda a las prácticas de camuflaje nominal de Moreno: Tom Lupo, que rescata el nombre de pila y la versión italianizada del apellido de Tom Wolfe, un nombre insoslayable del "new journalism" norteamericano. Sin dudas, esta experimentación nominal llega al extremo cuando nos encontramos en los créditos del segundo número con una colaboradora que firma como Elba Gallo: una sintaxis teñida de humor e ironía, pues aunque en una primera y rápida lectura "Elba" sea un nombre y "Gallo" un apellido muy común, desde el punto de vista fonético (y no gráfico) nos remite a "el bagayo", una expresión peyorativa para referirse a mujeres feas, que más que llevarnos a reponer su referente real (por ser un nombre y un apellido tan comunes podríamos encontrarnos con múltiples "Elba Gallo") nos envía a otras contraseñas de Moreno (en revistas sueltas firmó como Irene Motocicleta y Susy Kawasaki) ${ }^{27}$ y a la propuesta del popular álbum infantil de figuritas Basuritas de fines de los 80 y su juego de formación de otras palabras con la unión de las últimas sílabas de los nombres y los apellidos de sus personajes freaks como "Matilde Pilate" ("depilate"), "Matías Queroso" ("asqueroso") o "Roque Quejoso" ("quejoso").

La dirección periodística sólo del primer número de alfonsina está firmada por un imaginario "Mariana Imas": un compuesto que cruza la versión extendida del nombre María con un juego de palabras armado sobre el sintagma "y, más", que aunque se aprecia mejor en la oralidad, sugiere y pone de relieve,

${ }^{26}$ Véase Montana, Rosa. Marihuana Liberata. "Estado civil". alfonsina, 29/12/1983:8-9.

${ }^{27}$ Agradezco a Mayra Leciñana Blanchard por el aporte de éste y muchos otros datos sobre alfonsina. 
al menos, dos aspectos que interesan. Por un lado, el "y, más" esconde la frase " $\mathrm{y}$, habrá más" (propia de los finales de los folletines $y$ las historias por entregas que prometen una continuación), lo que nos transporta a esa voluntad de instalación de un comienzo, que vimos en el apartado anterior, y también a la confianza o al optimismo (Said:48) según los cuales el acto de comenzar sería un acto transitivo e implicaría una continuidad. Por otro lado, el "y, más" deja ver una sentencia: "y, somos más" que "Mariana", somos más que "María", somos más que una, y así se pone en juego, desde este primer número de la publicación, una de las estrategias que Moreno despliega para "hacer de autora". Precisamente, según Foucault (1969:98), la "función autor", además de ejercerse sobre un nombre, sobre la relación de apropiación y de atribución autorales, y en la posición del autor, habilita una proliferación de "egos", una pluralidad del "yo".

El retiro de portada del número 3 resulta provechoso para mostrar otros efectos de sentido que provocan las torsiones del "yo". En la columna izquierda se detallan, en orientación jerárquica, los créditos, que atribuyen la dirección periodística al (seudo)nombre María Moreno, y en la lista conjunta de colaboradores aparecen Mariana Imas y Rosa Montana, la periodista apócrifa creada por María Moreno-Martín Caparrós. Paradójicamente, al final de los créditos el director editorial consigna que "la responsabilidad de las notas firmadas corre por cuenta de sus autores". ¿A cuáles de los "yo", entonces, se responsabilizaría ante cualquier eventualidad editorial y legal por los escritos de signaturas ficticias? En la sección del costado derecho, llamada precisamente "Macedonia", entre otras notas, ${ }^{28}$

${ }^{28}$ En la misma página aparece una nota de Mariana Imas en donde cuenta una anécdota sobre un encuentro entre Dalí y una feminista española (Lidia Falcón) en una fiesta, en la que la feminista increpa al supuesto Dalí por impostor, por actuar como doble de Dalí. No por casualidad se incluye, casi matemáticamente, en esta sección otro género del "yo", una supuesta carta que Yourcenar le dedica a un caballero, en la que, al escribir, Yourcenar se dice estar "rodeada de seres nacidos de mi espíritu" y habitar una casita (una página del periódico) donde "hay un casi continuo ir y venir de seres". Véase: alfonsina,12/01/1984:2. 
Una poética del nombre

aparece una suerte de bio-bibliográfica, sin firma, motivadamente titulado "La periodista borrada", donde se presenta la trayectoria de Dolly Skefingtton, seudónimo de la poeta norteamericana Olivia Streethorse, de dudosa existencia, que es la protagonista de El affair Skefingtton (la novela que Moreno publicará casi 10 años más tarde, en 1992) y también se ofrece la traducción que de uno de sus poemas inéditos (acaso inventado por Moreno) realiza Rosa Montana. Una sección, en cuyo título, "Macedonia", además de la variedad y de la pluralidad de firmas mezcladas, quizá podría leerse una alusión y hasta un homenaje a uno de los escritores más inclasificables y escurridizos de la literatura argentina: Macedonio Fernández, el "escritor sin obra", "el escritor de la novela futura". Esta página que reúne un texto de Mariana Imas, una traducción hecha por Montana de un poema de Dolly Skefingtton, una poeta inventada, de quien dice la cronista que "algún día contaremos íntegra su verdadera historia" (alfonsina. 12/01/1984:2), podría pensarse como una puesta en abismo del arranque del proyecto estético de Moreno, que desde la primera página de la publicación encuentra un sistema provechoso de nombres, que da con los "buenos yoes", y anticipa un personaje de su texto futuro más experimental, un personaje que, vista su obra hacia atrás, funcionaría en términos de uno de esos personajes "preparados", esos "que vuelven", esos que Barthes, aunque a propósito de Proust, entendía como otro de los posibles disparadores de la escritura. Al mismo tiempo que Moreno en dicha sección tematiza los comienzos, entonces, anuncia un personaje de un texto aún por escribir. Y, como en una especie de juego de cajas chinas, para presentar a Dolly Skefingtton, la protagonista de su novela futura construida sobre la base de la imposibilidad de una atribución certera de la autoría, recurre al diseño de diferentes escenas de figuración del "yo" mediante estrategias de borramiento y multiplicación de su propia identidad autoral.

De igual modo, en el suplemento "La Mujer", Moreno diversifica sus firmas y suma al "María Moreno" otros seudónimos 
y/o heterónimos. Es probablemente Moreno quien firma como Cleo de Merode la columna que encabeza el suplemento. Un seudónimo que recupera el nombre de una célebre bailarina para presentar a las lectoras recetas de cocina dirigidas a cocineros con rasgos específicos, por ejemplo, una "sopa de almendras para cocineras sofisticadas" o la "carbonada de los solitarios cocineros". En "Señores", el suplemento de Tiempo argentino que dice estar dirigido a los hombres, pero que desde su título y en su formato y en la lista de colaboradores es casi un remedo de "La Mujer", Moreno rubrica algunas de sus intervenciones como Juan González Carballo. Este heterónimo le permite no sólo disimularse bajo otro nombre sino también producir textos desde la perspectiva impostada de un "varón machista", un enfoque "políticamente incorrecto" para la impulsora y creadora de "La Mujer", el "primer" suplemento feminista y de alfonsina, el "primer periódico para mujeres". Desde la forjada personalidad de Juan González Carballo, escribe, por ejemplo, un divertido decálogo de consejos prácticos para el hombre que pretenda emanciparse de las mujeres, entre otros, volverse físicamente desagradable o sexualmente no apetecible (Señores, 17/04/1984:2). En la piel de este "varón", la cara opuesta de Moreno tanto genérica como ideológicamente, también suscribe en un número de "La Mujer" una acotación a la nota principal sobre las vamp, a quienes redime de su condición de "matahombres" para dar lugar a una crítica enfocada a las otras mujeres, las "no vamp", que al poner en la mira la extravagancia de las vampiresas sólo expresan la intención de apropiarse de sus prácticas y deseos. Un claro ejemplo, entonces, de las transacciones y las operaciones de negación o difuminación de género que Moreno apuntaba como un inevitable rito de iniciación en la escritura.

No obstante, tanto en el periódico como en el suplemento y siempre dentro de la lógica del repliegue que implica el uso del seudónimo, es también María Moreno, o sus iniciales, una rúbrica repetida. En "La Mujer" suscribe la nota "Las que no se atreven: las chicas tipo Hamlet" ("La Mujer", 17/03/1984), en la que 
Una poética del nombre

reflexiona sobre los alcances de lo que significa para una mujer y para el resto de la sociedad atreverse a trabajar fuera del hogar y ser madres, a casarse y/o divorciarse, a irse de la casa paterna, a vivir solas y probar suerte. Desde esa misma identidad textual y autoral, la de la directora de un suplemento de avanzada, es María Moreno la que increpa al presidente de los argentinos, presenta temas y casos polémicos para la época (como el divorcio y el aborto) y recurre, también, al caso de Victoria Ocampo y el peronismo para poner entre signos de preguntas $y$ en tono condicional una idea de comienzo, la del comienzo rezagado del feminismo:

¿Podemos decir (...) que si Victoria Ocampo se hubiera puesto a pensar con menos pelo de mono el fenómeno peronista, el feminismo hoy no sería lo recién comenzado que es?

Con la misma contraseña, "María Moreno", firma en alfonsina, además de la dirección periodística desde la segunda entrega, una serie de notas controversiales. Desde esa identidad participa, encolerizada, de ciertos debates que impugnan el derecho al aborto, pero siempre atravesados por una articulación entre "lo femenino" y "lo nacional", por la retórica y el pasado políticos más inmediatos:

Una madre que aborta sería equivalente, si no he entendido mal, a los generales del Proceso (...) De lo que se deduce que los embriones que no han alcanzado la vida serían homologables a - la cita del general Camps y el genocidio que vivió la Argentina entre 1972 y 1980 lo sugieren- los argentinos puestos en parrilla en la Escuela de Mecánica de la Armada (alfonsina, 15/12/1983:16).

Con todo, la utilización o no de la forma María Moreno en alfonsina y "La Mujer" no permite establecer una ocurrencia metódica o reglada de esa firma, que, antes bien, pareciera ir 
reacomodándose a la deriva, complejizando entonces las colocaciones autorales de un mismo sujeto femenino, que al tiempo que protagoniza el acto de fundación del "primer periódico para mujeres" no duda en apropiarse del apellido de un ex marido para figurar públicamente, ni vacila en inventar un alter ego masculino y discordante para escribir en un suplemento feminista de vanguardia. Quizá una muestra, una respuesta, o una apuesta ante las dificultades y condicionamientos latentes a la hora de empezar a aprehender una serie de temáticas y comenzar a transitar por espacios nuevos desde la posición de una única identidad: nominal, de género e incluso de personalidad

\section{Más allá de los comienzos}

El significado del impulso entusiasta, ante todo de alfonsina, por ser el primero de una serie y el porqué de su apresurado fin son difíciles de explicar. Aparte de inscribirlos en el ambiente de euforia que la vuelta de la democracia representaba y que en poco tiempo decaen, como propone Luis Alberto Romero (2007:244), cuando esa ilusión democrática encuentra frenos y obstáculos desde distintos frentes, podemos sospechar, más en alfonsina que en Tiempo Argentino, cuyo cierre está teñido de complejas circunstancias políticas, un fin abrupto $^{29}$ pero esperable. Un periódico del "under" que fue producto más de un "golpe de pasión", como ha dicho Tom Lupo, ${ }^{30}$ sin un proyecto de marketing que le diera solvencia y le prometiera continuidad.

En ese marco, quizá el desafío y el atractivo mayores del "proyecto Moreno" estén en diseñar una estrategia de corrosión del nombre propio en publicaciones que se pretenden precursoras y reivindicatorias, en las que lo esperable acaso sería la plena

${ }^{29}$ En el número 11 de junio de 1984 hay una sección en la que se anuncia un adelanto del próximo número, lo que deja ver que, aunque ése fue el último ejemplar que salió de alfonsina, no se pensaba en ese momento en un inmediato cierre, o, al menos, no se le notifica a los lectores.

${ }^{30}$ Moreno, María. La voz del estadio. "Radar”. Página 12, 17/11/ 2002. 
Una poética del nombre

identificación y no el disfraz de la firma. En un gesto de "muchacha punk", Moreno elige en plena democracia usar su "nombre de guerra" que adquiere muy pronto el estatuto de "nombre de autora". Con todo, esta adhesión irreverente o, quizá, anacrónica a lo que la misma Moreno ${ }^{31}$-aunque a propósito del uso de pelucas en la película Los Rubios de Albertina Carridenomina la "cosmética de la clandestinidad" puede pensarse procesada y atravesada por la estética del movimiento artístico del underground, tan característico del momento y tan cercano a Moreno. En este sentido, una de las facetas del uso del seudónimo, antes que sólo encubrir un nombre civil y remitirnos a una usanza de la vida en clandestinidad, puede pensarse también en términos de un destape de la estética de la sobreimpresión, del sobre relieve o de la sobre piel (máscaras, maquillaje, prótesis, disfraces) del escenario del under.

Dijimos que es en alfonsina y "La Mujer" donde esas estrategias, antes dispersas, "cuajan" y permiten trazar un comienzo, desde el cual se expanden hacia la obra posterior. Veamos dos ejemplos.

Su novela El affaire Skeffington (1992) es una muestra de las maniobras extra e intratextuales de exposición y disimulo de la autoría. El libro está firmado por la autora María Moreno, no obstante, en el ángulo superior de la portada esa primera figuración autoral se ve escoltada por el nombre civil (Cristina Forero), al que se encierra entre paréntesis y, por ello, es sensible a una doble lectura conforme a los usos de este signo de puntuación: el nombre Cristina Forero sería aclaratorio de María Moreno pero también opcional o prescindible en la lectura. Ahora bien, en la contraportada de la edición de esta novela se lleva adelante una disociación. Así, es María Cristina Forero, sin los paréntesis, el nombre sobre el cual se hace foco para dar información biográfica: "nació en Buenos Aires en 1947", pero es

${ }^{31}$ Moreno, María. Esa rubia debilidad. "Radar". Página 12, 19/10/2003. 
María Moreno la firma que la conecta con su trayectoria periodística, la contraseña habitual de figuración pública.

En el orden de las representaciones, El affaire Skeffington, una suerte de glosa ficcional de los poemas de "una total desconocida", es un punto de inflexión sobre el problema de lo que Foucault llama la atribución autoral, la que se dirime, como reza la contraportada, ${ }^{32}$ entre cuatro heterónimos que, como en un juego de espejos, entran en diálogo: María Moreno/Cristina Forero, Dolly Skeffington/ Olivia Streethorse, o en el orden en que se prefiera.

En la misma línea, "El loro de Forero", una crónica del libro Banco a la sombra (2007), suscrito por María Moreno, insiste desde el título en el anclaje en el apellido paterno y deja ver otras estrategias de figuración. Toda la crónica sortea la narración de las impresiones "in situ" del yo/autor/cronista y se cifra en una ceremonia de duelo por la muerte de un nombre en común: Forero, el padre de María Moreno. Se trata menos, entonces, de un relato que se propone desde el género (genre) como dador de "verdad" etnográfica, la que proviene de la experiencia de la cronista (que no es otra que la autora) en tierra ajena, que del intento por exorcizar un cúmulo de angustias auto referenciales, las de una hija que acaba de ver morir a su padre y busca la forma de verlo renacer en el relato de los ritos vernáculos del Día de Muertos. Así, sus intentos previos de vaciarse del nombre que figura en sus documentos de identidad (Moreno, 2007:46) para hacer de autora toman un giro inverso en este cruce de crónica y relato ficcional, donde a pesar de ser María Moreno quien "da fe" sobre esos relatos, inscribe su paradero textual y extra textual en el apellido paterno. Y lo hace mediante "una broma literaria" (2007:46) que fusiona rítmicamente al loro de Flaubert -¿un padre literario?- con el loro de Forero.

32 María Moreno (1992): "María Moreno (María Cristina Forero) revela a los lectores la vida y la obra de Dolly Skeffington (Olivia Streethorse), en una heteronimia cuádruple...". 
Una poética del nombre

Así como esas estrategias de figuración que definían los comienzos de Moreno se continúan con variantes en otras zonas de su producción, el gesto fundacional de precisamente iniciar una tradición de periódicos o suplementos que se hagan cargo por vez primera y de manera genuina de sus problemáticas aparece en, por lo menos, dos de las últimas actuaciones periodísticas y gestiones culturales. Sin multiplicarse ya más que en un único seudónimo que ha reemplazado al nombre legal, es María Moreno la responsable de los números inaugurales de la clínica periodística de El Teje, el primer periódico travesti latinoamericano. Una publicación reciente, de circulación restringida ${ }^{33}$, dirigida por la activista trans Marlene Wayar, cuyo monumental tamaño va en paralelo con la voluntad de hacer visible las demandas $y$ problemas cotidianos de las personas transgenéricas. Este periódico se define como el primer periódico, no tan sólo argentino sino también latinoamericano, concebido, elaborado y redactado desde un lugar de enunciación travesti. En menor escala, en "Soy", el suplemento de los viernes que Página/12 saca desde marzo de 2008, que se pretende como el primer suplemento cultural de un diario de circulación masiva dedicado a poner en primer plano las cuestiones de diversidad sexual LGBT (lesbianas, gays, bisexuales y trans), también se registra la colaboración de la firma "María Moreno" con, entre otras varias, una nota homenaje ni más ni menos que a Néstor Perlongher, la Rosa L. de Grossman de alfonsina.

Estas intervenciones en El Teje y "Soy", publicaciones ambas que se proponen también como pioneras en lo suyo, reafirman hoy el gesto fundacional de María Moreno. Un seudónimo que, aunque oficialmente no le permita retirar de la oficina del Correo las encomiendas que quienes la confunden le

${ }^{33} \mathrm{El}$ Teje se consigue en el Centro Cultural Ricardo Rojas (Universidad de Buenos Aires) en la ciudad de Buenos Aires. Es trimestral y de distribución gratuita. 
remiten a "María Moreno", ${ }^{34}$ lejos está hoy de funcionar como enmascaramiento de la identidad. Antes bien, y aunque resulte a primera vista una paradoja, el seudónimo funcionaría ahora como uno de los puntos de aplicación del proceso de afianzamiento de la singularidad del escritor moderno (Nathalie Heinich, 2000), que pretende "salir de sî", que se dice autónomo y que, al propender el autoengendramiento ${ }^{35}$ creativo, siquiera nominal, se posiciona fuera de cualquier alienación civilmente impuesta.

En contraste con esos proyectos de comienzos de los 80, la periodista hoy consagrada, el nombre de autora "María Moreno" parecería ya no necesitar multiplicarse o, aun más, revertirse genéricamente, para instalar su voz en diversos ámbitos de la escena cultural argentina contemporánea.

\section{Referências bibliograficas}

AuzA, Néstor. Periodismo y feminismo en la Argentina (1830-1930). Buenos Aires, Emecé, 1998.

BARTHES, Roland. La preparación de la novela. Notas de cursos y seminarios en el Collège de France, 1978-1979 y 1979-1980. Buenos Aires, Siglo XXI, 2005 [2004].

BATTICUORE, Graciela, La mujer romántica. Lectoras, autoras y escritores en la Argentina (1830 - 1870). Buenos Aires, Edhasa, 2005.

BRUNN, Alain. L'auteur. París, GF Flammarion (col. Corpus), 2001.

Diz, Tania. Alfonsina periodista: Ironía y sexualidad en la prensa argentina (1915-1925). Buenos Aires, Libros del Rojas/Universidad de Buenos Aires, 2006.

Diz, Tania. Tensiones, genealogías y feminismos en los 80. Un acercamiento a alfonsina, primer periódico para mujeres. Mora, $\mathrm{n}^{\circ}$ 17, Buenos Aires, Facultad de Filosofía y Letras, 2011 (en prensa).

\footnotetext{
${ }^{34}$ Esta anécdota fue contada por María Moreno en uno de los talleres de crónica que impartió durante octubre y noviembre de 2008.

${ }^{35}$ Sigo la idea de autoengendramiento que desarrolla Nora Domínguez (2007).
} 
Una poética del nombre

DOMINGUEZ, Nora. De donde vienen los niños. Maternidad y escritura en la cultura argentina. Beatriz Viterbo, Buenos Aires, 2007.

ESCALES, Vanina. La marca de un flequillo. http://www.artemisanoticias. com.ar/site/notas.asp?id=50\&idnota $=1509$

FLETCHER, Lea. Hitos en el periodismo de mujeres argentinas: 18302007. En: CHAER, Sandra y SANTORO, Sonia. (comp.) Las palabras tienen sexo. Introducción a un periodismo con perspectiva de género. Buenos Aires, Artemisa Comunicación Ediciones, 2007, pp. 78-94.

FoUCAULT, Michel. ¿Qué es un autor? [1969]. Conjetural 4. 08/1984, pp. 87-111.

GioRDANO, Alberto. María Moreno: la entrada en la cultura. Otra Parte. Buenos Aires, otoño 2008, pp.60-64.

Gramuglio, María Teresa. La construcción de la imagen. En: Tizón, Héctor, RaBANAL, Rodolfo, Gramuglio, María Teresa. La escritura argentina. Universidad Nacional del Litoral, 1992.

HEINICH, Nathalie. Etre écrivain. Création et identité. París, La Découverte, 2000.

LINK, Daniel. Onda Góngora. Actitud María Moreno. Página 12, Buenos Aires, Radar Libros, 9/12/ 2001.

LOBATO, Mirta Zaida et alii. Historia con mujeres. Mujeres con Historia. Buenos Aires, Facultad de Filosofía y Letras, UBA, 2008.

MOLLOY, Silvia. Identidades textuales femeninas: estrategias de autofiguración. Mora, n 12, 12/2006, pp.68-86.

Moreno, María. Una lengua política. Soy, Página 12, 21/03/2008. http://www.pagina12.com.ar/diario/suplementos/soy/1-4-2008-0321.html.

. Banco a la sombra. Buenos Aires, Sudamericana, 2007.

. Vida de vivos. Conversaciones incidentales y retratos sin retocar. Buenos Aires, Sudamericana, 2005.

Sudamericana, 2002. 
. A tontas y a locas. Buenos Aires, Sudamericana, 2001.

. La chillona alegría de esa época. Suplemento Cultura y Nación, Clarín, 22/12/2001. . El affaire Skeffington. Rosario, Bajo la Luna, 1992.

PREMAT, Julio. (edit.) Figuras de autor. Saint Denis, Universidad de Paris 8, Vincennes, 2006.

PREMAT, Julio. Héroes sin atributos. Figuras de autor en la literatura argentina. Buenos Aires, Fondo de Cultura Económica, 2009.

RichARD, Nelly. Feminismo, género y diferencia(s). Santiago de Chile, Editorial Palinodia, 2008.

ROMERO, Luis Alberto. Breve Historia contemporánea de la Argentina (1994). Buenos Aires, Fondo de Cultura Económica, 2007.

RUSSOTO, Márgara. (comp.) La ansiedad autorial. Formación de la autoría femenina en América Latina: los textos autobiográficos. Caracas, Equinoccio, 2006.

SAID, Edward. W. Beginnings. Intention and Method. New York, Columbia University Press, 1985 [1975].

SARLO, Beatriz. Alfonsina, la poetisa. En: Una modernidad periférica: Buenos Aires 1920 y 1930. Buenos Aires, Nueva Visión, 1999, pp.78-85.

UlanovSKY, Carlos. Paren las rotativas. Buenos Aires, Espasa, 1997.

VAllejo, Soledad. En el molde. Las 12. Página 12, Buenos Aires, 24/03/2006.

\section{Publicaciones periódicas consultadas}

alfonsina, año $1, \mathrm{n}^{\circ} 1,2,3,4,5,6,7,8,9$ y 11, Buenos Aires, 15/12/1983 al 7/06/1984.

"La Mujer", suplemento del diario Tiempo Argentino, Buenos Aires. Se revisaron los números contemporáneos a la salida del periódico alfonsina: desde el 3/12/1983 al 30/06/1984. 
Una poética del nombre

El Teje. Primer periódico travesti latinoamericano, Centro Cultural Ricardo Rojas, Universidad de Buenos Aires, año 1, nº 1, 11/ 2007.

"Soy" de Página 12, Buenos Aires, n 1, 21/03/ 2008. 